\title{
Open source solutions for Librarian
}

\author{
Dakshata Avinash Dukare \\ Junior Librarian, M. P. Birla Library \& Information Centre, Bombay Hospital Trust, Mumbai, Maharashtra, India \\ *Corresponding Author: Dakshata Avinash Dukare \\ Email: unde_dakshata@rediffmail.com
}

\begin{abstract}
Open source software is software that users have the ability to run, copy, distribute, study, modify, share, and improve for any purpose. Open source library software does not need the initial cost of commercial software, but it does allow libraries to have more control over their working environment. Library professionals should be vigilant. The advantages of open source software and should involve its development. They must have basic knowledge. In the selection, installation and maintenance. Open source software requires more processing responsibility for commercial software. Library professionals do not seriously think about the benefits of opening source code software for automation and are therefore reluctant to use it. Lacking the skills to support open source software, the document highlights the core software of the open source library.
\end{abstract}

Keywords: Open source software's, The open source movement, Library technology, Information technology.

\section{Introduction}

What is open source software technology?

Open source software is software whose source code is available under a license (or public domain agreement) that allows users to study, change and improve the software and redistribute it to a modified or unmodified company. It is often developed in a public and collaborative way. It is the most important example of open source development and is often compared to user generated content. For many libraries, organizing their books and other media can be a daunting task, especially as the library grows with more material. Years ago, we had raw paper catalog systems (remember the Dewey Decimal System) that kept things organized, but were difficult to maintain. With today's computer technology, organizing our libraries has never been easier or more efficient. The card catalog is finished, and in some libraries, it is much easier to find a book and an Internet connection and pick it up on arrival, rather than wasting time searching the lanes for the next reading. Now, just because the world has been blessed with wonderful software solutions that make everything easier to do doesn't mean that every library in the universe is using these solutions. Many libraries do not have large amounts of money to spend, and what they usually get is to buy additional resources. Due to this need for software (and the installation and training costs associated with anyone) and the lack of money available to spend on it, many libraries are left alone when it comes to keeping up with the latest technologies. Unless, of course, they embrace the open source movement and use some of the myriad software solutions available to help. Most of the software we use every day is known as "proprietary," which in summary means that it costs money and that the actual software code is limited because the software code cannot be edited, copied, or changed. Its original construction. The code is "unreadable" and it is practically what it is. Open source software, on the other hand, is the exact opposite. The open source mindset revolves around sharing and collaboration, and these two important elements perfectly describe open source software. First of all, open source software is free for everyone; More importantly, not only is the software free, it is also free for anyone to copy, hack, edit, etc. This increases the potential of a software program thanks to this free-thinking model. Many large developer groups have customized basic open source programs to what they deem necessary, and in turn have returned these changes to the open source community for free, where others can continue to develop their work. There are many different types of open source software solutions today that could be accepted by the library. There is a basic operating system, document processing programs, library management software (LMS), and digital library software.

"Open source promotes the reliability and quality of software by supporting independent peer review and the rapid evolution of source code. To be certified as open source, a program license must guarantee the right to read, redistribute, modify, and use it freely"

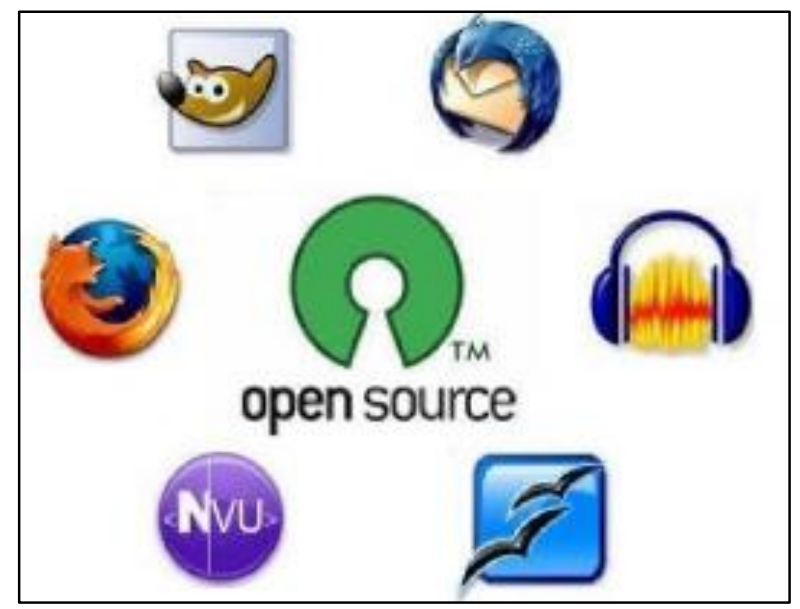

Fig. 1:

Source: http://www.opensource.org/

\section{Advantages of open source software}

1. Lower software costs: Open source solutions generally do not require license costs. The logical. The extension 
does not include maintenance costs. The only costs are for media, documentation and support if needed.

2. Simplified license management: download the software once and install it as many times as you like. Many places you need. No need to count, track, or monitor license compliance.

3. Lower hardware costs: Overall, Linux and open source solutions are elegantly compact and portable and therefore requires less hardware power to perform the same tasks as conventional servers (Windows, Solaris) or workstations. The result is that you can survive on less expensive or old hardware.

4. Reduction / Consolidation Potential: Even in this case, Linux and Open Source applications and services can do it. It is often significantly reduced. Multiple options for load balancing, pooling, and open source applications, such as databases and email, give organizations the ability to scale new ones. Growth or consolidation to do more with less.

5. Support: Support is available for open source solutions, often superior to proprietary solutions. First, Open source support is available for free and accessible through the online community through Internet. And second, many tech companies now support open source with free and online services. Multiple levels of paid support. For example, Liblime.

6. Vendor Escape Freeze: The frustration of vendor freezing is a reality for all IT managers. In addition to ongoing licensing costs, portability, and the inability to customize the lack of software to meet specific needs. Open source exists as a declaration of freedom of choice.

7. Unified management: specific open source technologies such as CIM (Common Information Model) and WBEM (Web Based Enterprise Management) offer the possibility of integrating or consolidating the management of servers, services, applications and workstations for high administration power.

8. Quality software: Evidence and research indicate that open source software is a good thing. He peer review process and community standards, plus the fact that the source code is available for To see the world, they tend to drive design excellence and coding efficiency.

\section{Open source software for libraries \\ Library automation}

Koha: integrated library system

Koha is a promising open source

ILS (Integrated Library System)

that libraries around the world

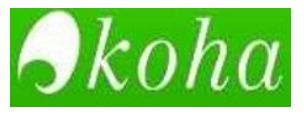

currently use. For those of you It is not known what an ILS is, well, it is a system to track library operations: payment receipts, expenses, purchases and, above all, keep track of the various means controlled by the clients of the librarians. Many smaller libraries cannot afford to purchase, install and maintain an ILS and Koha is a perfect alternative. Koha was created using the ILS library standards and uses the Open Public Access Catalog (OPAC) interface. Plus, Koha doesn't have vendor blocking, so libraries can get technical support from anywhere they choose.

\section{New Gen Lib}

New Gen Lib (New Generation Library) is an integrated library network and automation solution developed by Verus Solutions Pvt Ltd and The Kesavan Institute of Information and Knowledge Management, India. NewGenLib version 1.0 was released in March 2005 and later versions 2.0 and 2.1 were released. On January 9, 2008 NewGenLib has open source software licensed under the GNU GPL was stated by Verus Solutions Pvt Ltd, Hyderabad, India.

\section{Evergreen}

Evergreen ILS is another option for finding open source ILS options. Developed by Equinox

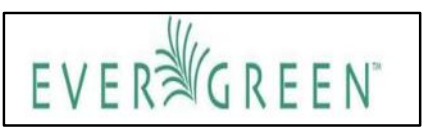

Software, Evergreen is a robust business-class ILS solution developed to provide support. The workload of large libraries in a fault tolerant system. This is also standards compliant and uses the OPAC interface and offers many features including flexible administration, workflow customization, customizable programming interfaces and since they are open source they cannot be blocked and can benefit from your contributions from the community.

\section{Digital library \\ Greenstone Digital Library Software}

Greenstone digital library software is an open source system for creating and presenting collections of information. Create collections

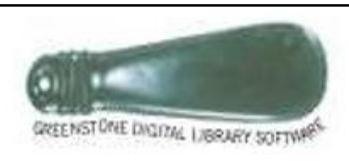
with effective full-text searches and metadata-based navigation services that are attractive and easy to use. Furthermore, they are easily maintained and can be Fully expanded and rebuilt automatically. The system is extensible: software "plug-ins" can contain different types of documents and metadata. The purpose of Greenstone software is to allow users, especially in universities, libraries, and other public service institutions, to create their own digital libraries.

\section{DSpace}

Dspace is an innovative digital institutional repository that captures, archives, indexes, preserves and redistributes the

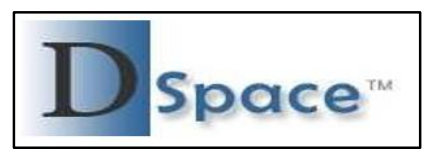
intellectual output of a university's research faculty in digital formats. Manages and distributes digital articles, which consist of digital files and allows the creation, indexing, and search for associated metadata to locate and retrieve items. Design and development of DSpace from the Massachusetts Institute of Technology (MIT) and Hewlett-Packard (HP) 
libraries. DSpace was designed as an open source application that institutions and organizations could run with relatively few resources. It is used to support the long-term retention of digital material stored in the repository. It is also designed to facilitate shipping. DSpace supports sending, managing and accessing digital content.

\section{Fingerprints}

Eprints is an open source software package for creating open access repositories that comply with the open file

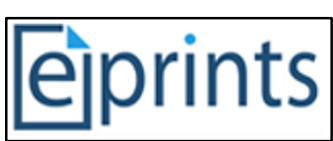
archiving protocol for metadata collection. It shares many of the features commonly seen in document management systems, but is used primarily for institutional purposes. Repositories and scientific journals. EPrints was developed at the University of Southampton College of Electronics and Computing and was released under the GPL license.

\section{Fedora}

Fedora's open source software provides organizations with a flexible, serviceoriented architecture to manage and distribute their digital content. At its core is a powerful digital object model

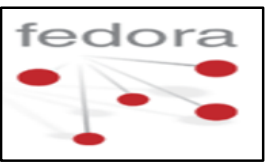
that supports multiple views of each digital object and the relationships between digital objects. Digital objects can be encapsulated in locally managed content or display remote content. Dynamic views are possible by associating web services with objects. Digital objects exist within a repository architecture that supports a variety of management functions.

All Fedora functions, both object level and repository level, are exposed as web services. These functions can be protected with specific access control criteria. This unique combination of features makes Fedora an attractive solution in a variety of domains. Examples of Fedora-based applications include library collection management, media authoring systems, file repositories, institutional repositories, and digital libraries for education.

\section{Publication on the web Word Press}

WordPress was born as a fast, free and open source blogging solution a few years ago; Today is a perfect alternative to create a website from scratch. In addition to being free (and easy to install), the WordPress

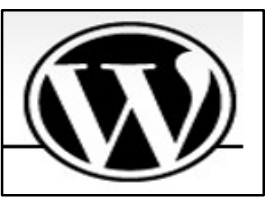
community has exploded, with thousands of users and programmers creating custom themes and plugins to modify the appearance and operation of the software. The most important aspect of the software is the intuitive interface and the content management system. With its visually rich editor, anyone can post text and photos on the website. Other options include multiple authors (with separate logins), integrated Real Simple Syndication (RSS) technology to keep subscribers up-to-date, and a comment system that allows readers to interact with site content. A great way to communicate with users, staff, etc.

\section{Drupal}

Drupal is another open source web publishing option that allows a person or community of users to easily publish, manage and organize a wide range of content on a website. Tens of thousands

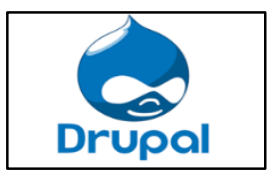
of people and organizations have used Drupal to feed dozens of different websites, including community web portals, discussion sites, corporate websites, intranet apps, personal websites or blogs, e-commerce apps, resource lists, social networking sites.

\author{
Development of web applications with CMS \\ Content management \\ User Management \\ Joomla Media Manager - (ww.joomla.org) \\ Banner Management Word press - (www.wordpress.org) and \\ (www.wordpress.com) \\ Drupal Research Link - (www.drupal.org) \\ RSS Kompozer (http://kompozer.net) \\ Menu management \\ Model management \\ Plugins and community support
}

\section{Advantages of open source software}

1. Ability to adapt to local needs: the availability of the source code means that a user can modify and improve the software to better adapt to their needs.

2. No restrictions on use: There are no contractual restrictions on the use of the software.

3. Low cost: There is no charge for the software itself. The biggest cost is local development. If the number of users is high and they share their efforts, the cost of each user is reduced.

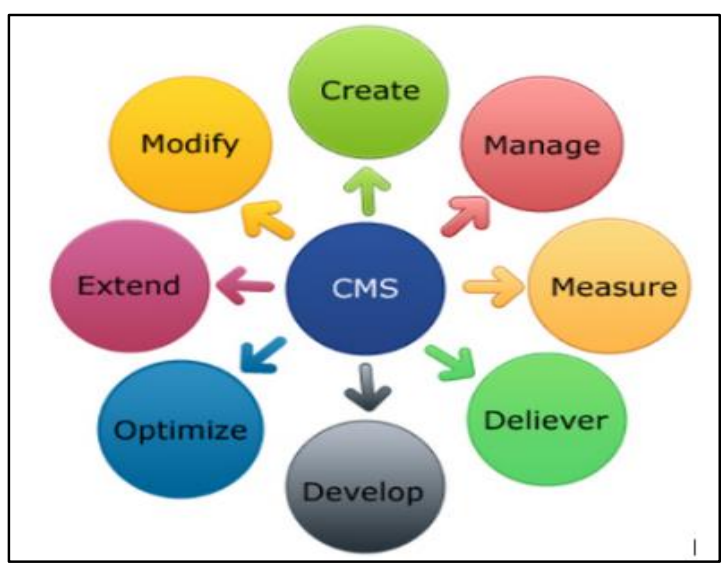

Fig. 2:

Disadvantages of open source software

1. Unexpected commitments: A library may find that it needs to do much more work than expected to adapt the software to local needs. 
2. Lack of coordination: The decentralized development of open source software means that progress can be chaotic and there can be delays in error handling.

3. Inadequate technical support: Documentation tends to be limited and aimed at developers. Technical support is generally limited, especially for users of the software.

4. Personalization: Open source software may not offer the level of personalization that is available for commercial software.

\section{Open source software: Challenges}

1. Requires technical knowledge and experience.

2. The attached documentation is generally poor.

3. It is difficult to get paid support for new software.

4. There is little coordination between hardware vendors and the open source community.

5. Librarians are used for proprietary software applications built on or running on the Microsoft Windows platform.

6. You may have already invested a lot of money and efforts to create automated systems over a period of time.

If you wish to install the software on your own server, many open source software is available for providing library 2.0 services. Here are some of the most popular OSS.

\begin{tabular}{|c|c|c|}
\hline Category & OSS & $\begin{array}{c}\text { Free Hosting Web } \\
\text { Sites }\end{array}$ \\
\hline Blogs & $\begin{array}{c}\text { WordPress } \\
\text { Drupal } \\
\text { LiveJournal }\end{array}$ & $\begin{array}{c}\text { Blogger.com } \\
\text { WordPress.org }\end{array}$ \\
\hline Wikis & MediaWiki & WikiSpaces \\
& TWiki; & \\
\hline PHPW feeds & RSSOwl reader & Google Reader \\
& QuickRSS & Facebook, \\
Social & SOPAC & YouTube \\
Networking & PHPBB & Flickr \\
& Drupal & \\
& &
\end{tabular}

\section{Conclusion}

Using open source software is as good as owning it. Applicant suitable for long-term use of the library.

It is worth spending time and energy on learning and adoption. Therefore, it seems that there are some very powerful solutions available today that could be used to create a much more entrepreneurial library. By using open source software in the library, money that would otherwise be spent on software solutions can be used for other important resources, such as the purchase of additional multimedia resources (books, magazines, etc.), or You can use it to recruit qualified Technical Support personnel who provide users with knowledge on how to make better use of existing resources. Additionally, this free software is constantly updated, modified, and customized to meet the needs of the library. While this is all good and stylish, and sounds like the advantageous solution for your library, there are still hurdles and hurdles that we will have to overcome. I hope this article provides introductory information on how to separate your library from traditional IT products and immerse yourself in the set of open source resources available today.

\section{Source of Funding}

None.

\section{Conflict of Interest}

None.

\section{References}

1. Micah A. (2001). Open Source Software for Libraries: from Greenstone to the Virtual Data Center and Beyond. IASSIST Quarterly, Winter 2001, 5-11. Retrieved July 17, 2020, from Web site:

http://iassistdata.org/publications/iq/iq25/iqvol254altman.pdf

2. Bailey, Charles W., Jr. (2006). Open Access and Libraries. Retrieved July 15, 2020, from Web site: http://www.digitalscholarship.com/cwb/OALibraries2.pdf

3. Balas, Janet L. (2004). Considering open source software. Computers in Libraries. 24 (8), 36-39. Retrieved July 10, 2020, from Web site:

http://www.infotoday.com/cilmag/sep04/balas.shtml

4. Bretthauer, David (2002). Open Source Software: A History. ITAL: Information Technology and Libraries. 21(1),3-11. Retrieved July 16th 2020, from Web site: http://www.ala.org/ala/lita/litapublications/ital/2101bretthauer. $\mathrm{cfm}$

5. Corrado, Edward M. (2005). The Importance of Open Access, Open Source, and Open Standards for Libraries. Issues in Science \& Technology Librarianship. 42. Retrieved July 16, 2020, from Web site: http://www.istl.org/05spring/article2.html

6. Ferraro, Joshua. (2006). Why Your Library Needs Open Source. Retrieved July 15, 2020, from Web site: http://liblime.com/c/welcome.html

7. Retrieved July 17, 2020, from Web site: http://eprints.rclis.org/13172/1/Open_Source_Software_and_Li braries.pdf

8. Retrieved July 17, 2020, from Web site:https://www.dotsquares.com/solutions/web-applicationdevelopment/cms-applications/

9. Retrieved July 17, 2020, from Web site:http://knowgate.niscair.res.in/documents/10181/21379/01Open+source+software+for+libraries.pdf/015ffe4d-75a6-4d138f82-74b5f575add4

How to cite: Dukare DA. Open source solutions for Librarian. IP Indian J Libr Sci Inf Techno 2020;5(1):50-3. 